\title{
USING INTELLIGENT TECHNIQUE RBFNN FOR PREDICTION RECOGNITION OF TOOL WEAR IN HARD TURNING
}

\author{
Akeel Ali Wannas \\ Mechanical Engineering Department, University of Technology \\ (Received: 27/7/2011; Accepted: 17/10/2012)
}

\begin{abstract}
Hard turning technology has been gaining acceptance in many industries throughout the last 2 decades. The trend today is to replace the slow and cost-intensive grinding process with finish hard turning in many industrial applications such as bearings, transmission shafts, axles and engine components, flap gears, landing struts and aerospace engine components. In this study, Radial Basis Function Neural Network (RBFNN) model has been developed for the prediction of the status of the tool wear. Learning data was collected from Experimental setup. The neural network model has 3 input nodes and one output representing process Modeling correlates process state variables to parameters. The process input parameters are Feed rate $(F)$, cutting Speed $(S)$ and Depth of cut $\left(D_{c}\right)$. The process output is state Variable $\left(\mathrm{V}_{\mathrm{b}}\right)$. Regression analysis between finite element results and values predicted by the neural network model shows the least error.
\end{abstract}

Keywords: -RBFNN, wear, hard turning, applications, transmission, components.

\section{INTRODUCTION}

Due to its favorable effects on the machined surface, hard turning processes are replacing grinding for finishing various mechanical components of hardened steels such as transmission shafts, bearings and gears for the automotive industry, as well as landing gear struts for the aerospace industry. During hard turning, the cutting tool, usually from Cubic Boron Nitride $(\mathrm{CBN})$, is exposed to a very severe environment. In all these machines, predefined sequence of instruction, like using stops and programming methods, is used to execute the operations, so that good quality parts with mass production are achieved. For a 
tool to perform successfully under these severe conditions factors such as the cutting tool edge geometry (chamfer angle and hone radius), feed rate and cutting speed have to be carefully selected.

In the past decades, the mechanics of metal cutting processes have been extensively investigated through numerical and experimental techniques with encouraging achievements. A major application of the hard turning process is the bearing industry, where a sequence of production steps, including heat treatment and grinding, are traditionally required to produce bearing races out of medium-and high-carbon steels (e.g., AISI 1050, 52100, ASTM 5115). The trend today is to replace the slow and cost-intensive grinding process with the turning process to directly rough and finish machining hardened bearing components prior to super finishing. Also, automobile makers have started to use hard turning for semi-finished and finished transmission shafts, axles and engine components, while aircraft manufacturers have applied the technology to the production of flap gears, landing struts and aerospace engine components ${ }^{(1)}$.

Another industrial example of such a transition from grinding to hard turning is the production of T1 N drive shafts of the Mercedes Benz Sprinter, which is made of hardened AISI 1045 (61 HRC) ${ }^{(2)}$. When compared to grinding, the most significant advantage of hard turning is the generation of relatively deep surface compressive residual stresses ${ }^{(3,4,5}$, and 6$)$.

In addition, hard turning has several potential advantages over grinding, such as the ability to machine complex workpiece geometry in one set-up, the low capital investment cost and risks, the ability to be environment-friendly since coolants are avoided, easy and fast set up and lower energy consumption ${ }^{(7)}$.

Due to the complexity and unpredictable nature of the machine process, the process has to be modeled with rule-based techniques. Therefore, this study focus on RBFNN Modeling correlates process state variables to parameters. The duration, after which a tool has to be replaced or reground, can be expressed in terms of amount of flank wear land width of the tool $\left(\mathrm{V}_{\mathrm{b}}\right)$ or tool life in minutes. When the tools are worn out, they are replaced with new tools, or reground and used. Established data both in terms of tool life and amount of tool wear, are available, based on which, the tools can be replaced or reground. The process state variable is $\mathrm{Vb}$. The process parameters are feed rate $(\mathrm{F})$, cutting Speed $(\mathrm{S})$ and Depth of cut $\left(\mathrm{D}_{\mathrm{c}}\right)$. Some of the modeling techniques are multiple regression analysis and group method data handling. These methods require a relationship between process parameters and process state variables ${ }^{[8]}$. The neural network approach does not require any modeling between process parameters and the outputs are process state variables. In addition, to the fundamental 
understanding of hard turning process and RBFNN, the present study will contribute to: Develop Robust Material Data for Hard Turning Modeling of AISI 52100. Determining experimental data that is suitable to training RBFNN of hard turning. Using RBFNN to enhance the cutting tool design through the prediction of tool wear.

\section{THEORETICAL BACKGROUND}

In general, for fundamental research, machining processes can be represented with 2 typical cutting models depending on tool geometry and tool orientation; these are called the orthogonal cutting model and the oblique cutting model.

If the cutting edge is perpendicular to the cutting speed direction and the uncut chip thickness is small compared to the width of cut (normally, w/tu $\geq 4$ ), chip formation in the deformation zone can then be considered as plane strain plastic deformation with no lateral material flow Figure (1).

Under this condition, the transversal Force component (FR) becomes negligible and thus a 2D orthogonal cutting model can be applied. As the chip separates from the workpiece, it passes through the shear plane where it is subject to severe plastic deformation before sliding up the rake face of the tool. There are three areas of interest in the cutting process Figure (2b), The shear plane Figure (1a) where the chip separates from the bulk material and severe plastic deformation occurs, (b) the interface between the chip and the rake face of the tool Figure (1b) where a large amount of heat is generated due to friction and the interface between the tool flank and the machined surface of the workpieceFigure (1c).

Three types of turning operations are commonly used in research to achieve the required orthogonal cutting conditions, as illustrated in Figure (2). In the case of conventional turning in Figure (2c), the nose radius of the tool needs to be chosen as small as possible in order to reduce the radial thrust force component $\left(\mathrm{F}_{\mathrm{R}}\right)$ such that the cutting process can be approximated as orthogonal cutting.

In conventional turning operations Figure (2c) of soft steels with moderate or large depths of cut, such as in roughing and semi-rough machining, a significant force.

Component is distinguishable in the tangential cutting speed direction. This result is mainly due to the severe plastic deformation during continuous chip formation, in which the ductile workpiece material is plastically sheared along the shear plane in front of the tool tip and forms a continuous chip. The produced chip exerts high normal and shear stresses on the tool face and generates high cutting temperatures caused by plastic deformation and friction 
at the tool-chip interface.

\section{3- MATERIALS AND METHODS}

Cutting tools for hard turning: In general, cutting tools used for hard turning require extreme hardness, high compressive strength, high resistance to abrasive wear, thermal resistance and chemical stability at elevate temperatures. For interrupted cuts, tool materials with high toughness are more frequently required to prevent chipping and edge failure; however, these materials tend to have lower wear resistance instead despite to avoiding the use of coolant, as it causes higher variation in temperature, leading to premature tool failure.

Ceramic and Cubic Boron Nitride $(\mathrm{CBN})$ tools are currently the only choices available that can meet the demands of turning hardened steels.

In most practical cases, two important criteria related to tool life are simultaneously used to evaluate the finishing performance of a hard turning process. They are attainable surface quality and tool wear Figure (3), which are directly influenced by the cutting tool material and geometry. Therefore, in order to prolong tool life and prevent edge failure, selection of the optimal tool material and edge preparation for each particular application is especially important. Flank wear should be controlled within a limit value, defined as the tool life criterion (e.g., Vbave $=0.2 \mathrm{~mm}$ ), as it causes degradation of surface finish and thermal damage on the machined surface due to tool-work friction. In addition, crater wear, which can occur near the cutting edge and weakens it, is also a significant failure mode in hard turning. Dry conditions are usually recommended for hard turning because coolant use may cause greater thermal shock in hard tool materials (e.g., ceramics) and induce chipping ${ }^{(3)}$.

Ceramic tools typically cost only $1 / 5-1 / 10$ the cost of a CBN tool and provide an inexpensive alternative for many hard turning applications. The typical ceramic tool used in hard turning is a composite material consisting of aluminum oxide and titanium carbide $(\mathrm{A} 12 \mathrm{O} 3+\mathrm{TiC})$. Ceramic tools can be used successfully in continuous cutting situations where the demands of dimensional accuracy are not too great. There are three main disadvantages of ceramic tools that limit their application in hard turning.

First, ceramic tools cannot provide consistent tool life for interrupted cutting, in which the tool must withstand high cyclic impact loading.

Second, the wear resistance of ceramic tools is considerably lower than that of CBN tools, thus requiring more frequent tool changes and closer monitoring of the process.

Third, the thermal conductivity of ceramic tools is very low (about $1 / 5$ that of CBN 
tools), which leads to higher temperatures in the cutting zone of the work material during cutting. High cutting temperatures at the workpiece can cause significant thermal distortion of the parts being machined.

\section{4- RBFNN MODEL PREDICTION}

From the examples ANN captures the domain knowledge. ANN can handle continuous as well as discrete data and have good generalization capability as with fuzzy expert systems. An ANN is a computational model of the brain. They assume that computation is distributed over several simple units called neurons, which are interconnected and operate in parallel thus known as parallel distributed processing systems or connectionist systems. Implicit knowledge is built into a neural network by training it. Several types of ANN structures and training algorithms have been proposed.

The basic form of RBF architecture involves entirely three different layers. The input layers is made $\mathrm{n}$, of source nodes while, the second layer is hidden layer of high enough dimension which senses a different purpose from that in a multilayer perception.

The output layer supplies the response of the network to the activation patterns applied to the input layer. The tram formation from the input layer to hidden is nonlinear whereas the transformation from the hidden from unit to the output layer is linear. The transfer function for a radial basis neuron is:

$$
\operatorname{radbas}(\mathrm{n})=\mathrm{e}_{-\mathrm{n} 2}
$$

This function calculates a layer's output from its net input.

For effective predicting of tool wear process, the selection of proper inputs and outputs of ANN, structure of the network and training of it using appropriate data should be done with utmost care. In the present study, inputs are selected as are Feed rate (F), cutting Speed $(S)$ and Depth of cut $\left(D_{c}\right)$. The process output is. The NN outputs have been termed as one output node representing the state variable $\left(\mathrm{V}_{\mathrm{b}}\right)$ as shown in Figure (4).

\section{5- RESULTS AND DISCUSSION}

Experimental study on Turing was conducted with spherical graphite cast iron work material. The tool used for this study is made of 13 layers of coating with ALON, Tic, TIN, $\mathrm{Ii}(\mathrm{C}, \mathrm{N})$ over a carbide substrate. The ranges of various process parameters are: Cutting speed (200-500 m min $\left.\mathrm{m}^{-1}\right)$, feed $\left(0.063-0.25 \mathrm{~mm} \mathrm{rev}^{-1}\right)$ and depth of cut (0.5-2 mm). The Turing operation was carried on a VDF high-speed precision lathe. 
The 3 components of forces, namely, axial Force $\left(F_{x}\right)$, radial Force $\left(F_{y}\right)$ and tangential Force $\left(\mathrm{F}_{\mathrm{z}}\right)$ and flank wear land width $\left(\mathrm{V}_{\mathrm{b}}\right)$ were collected. To read the cutting forces, a threecomponent piezoelectric crystal type of dynamometer (KISTLER type 9441) was used. The value of $\mathrm{V}_{\mathrm{b}}$ was measured by a toolmaker's microscope. The block diagram of the experimental set-up is shown in Figure (5).

Measurements were made at different intervals of time. Depending on the length of cut, machining was stopped after every 60-80 sec and $\mathrm{V}_{\mathrm{b}}$ was measured. Static forces were recorded at 2 or 3 intermediate points between 2 wear measurements. The set of measurements, immediately prior to a wear measurement, had been used for training the neural network. About 113 patterns were collected. During reinsertion of tool inserts after every wear measurement, inserts were slugged into the slot made out in the tool holder, so that there was no change in the tool overhang. About $90 \%$ of the data 101 patterns, were used to train the different network architectures, where remaining 12 patterns were used for testing to verify the prediction ability of each trained NN model. Since, RBFNNs Learn relations and approximate function mapping limited by the extent of the training data, the best use of the trained RBFNN models can be achieved in interpolation.

Table 1 shows the RBFNN output for prediction Tool wear, from the analysis of the results in Table (1); it is observed that the accuracy of the RBFNN method was slightly superior when compared to the experimental results on account of Mean Average Error (MAE). Figure (5) shows a plot of experimental result for wear tool against corresponding RBFNN prediction. A linear correlation can be observed and the correlation coefficient was found Table (1).

\section{6- CONCLUSION}

The overall goal of the proposed research is to develop methodologies using RBFNN for predicting the effects of the cutting tool edge design and the machined surface integrity on hard turning as follows:

* The hard turning process is being applied gradually in industry to replace the costly and slow grinding process in finishing mechanical components.

RBFNN proved to be an efficient tool to optimize several industrial metal forming processes. The use of RBFNN in modeling of machining allows for considering process details that analytical models cannot handle and for predicting variables.

Finally, the simulation results show that RBF can be very successively used for reduction of the effort and time required. This means that it can solve many problems that have 
mathematical and time difficulties.

\section{REFERENCES}

1- Hashimura, M., Y. Chang and D. Dornfeld, "Analysis of burr formation mechanism in orthogonal cutting”, J. Manufacturing Sci. Eng., 121: 1-7, 1999.

2- Reisner, S. and B. Vogt, "Process converted from grinding to hard fine turning" Ind. Diamond Rev., 3: 62-63/65, 2003.

3- Matsumoto, Y., F. Hashimoto and G. Lahoti, "Surface integrity generated by precision hard turning" Ann. College Int. Pour la Recherche en Producerique (CIRP), 48 (1): 59-62, 1999.

4- König, W., M. Klinger and R. Link, "Machining hard material with geometrically defined cutting edges-field of applications and limitations" Ann. College Int. Pour la Recherche en Producerique (CIRP), 39 (1): 61-64, 1990.

5- Liu, K. and S.N. Melkote, "Finite element analysis of the influence of tool edge radius on size effect in orthogonal micro-cutting process", Int. J. Mech. Sci., 49 (5): 650660, 2007.

6- Bagshaw, R.W. and S.T. Newman, "Manufacturing data analysis of machine tool errors within a contemporary small manufacturing enterprise", Int. J. Machine Tools Manufacture, 42 (9): 1065-1080, 2002.

7- Thiele, J., S. Melkote, R. Peascoe and T. Watkins, "Effect of cutting-edge geometry and workpiece hardness on surface residual stresses in finish hard turning of AISI 52100 steel”, Trans. ASME J. Manufacturing Sci. Eng., 122: 642-649, 2000.

8- Li, X. and X. Yao, "Multi-scale statistical process monitoring in machining", IEEE. Trans. Ind. Elec., 52 (3): 924-927. DOI: 10.1109/TIE.2005.847580, 2005.

9- Sohrab, K., I. Hassanzadeh and M.B.B. Sharifian, "Modified adaptive discrete control system containing neural estimator and neural controller", AI in Eng., 14 (1): 31-38. DOI: 10.1016/S0954-1810 (99)00017-5, 1999. 
Table (1): Sample of reduction tool wear

\begin{tabular}{|c|c|c|c|c|c|c|c|c|}
\hline \multirow[b]{2}{*}{$\begin{array}{l}\underset{1}{1} \\
\vdots \\
\vdots \\
\vdots \\
\text { s }\end{array}$} & \multicolumn{5}{|c|}{ Inputs } & \multicolumn{3}{|c|}{ Outputs } \\
\hline & 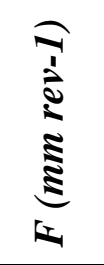 & $\frac{\widehat{\Xi}}{\mathfrak{\Xi}}$ & $\underset{z}{z}$ & 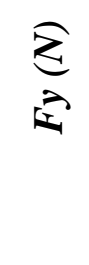 & $\underset{E^{N}}{\sum}$ & 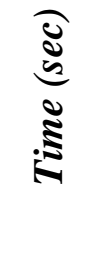 & 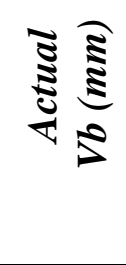 & 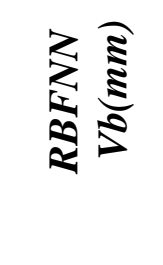 \\
\hline 450 & 0.10 & 1.5 & 150 & 350 & 115 & 45 & 15 & 14.9954 \\
\hline 450 & 0.10 & 0.5 & 60 & 115 & 50 & 38 & 15 & 15.0053 \\
\hline 450 & 0.10 & 2 & 180 & 450 & 130 & 32 & 15 & 15.0022 \\
\hline 350 & 0.10 & 0.5 & 60 & 125 & 90 & 30 & 15 & 14.9969 \\
\hline 300 & 0.06 & 0.5 & 45 & 70 & 80 & 428 & 20 & 19.9987 \\
\hline 300 & 0.06 & 0.5 & 40 & 65 & 80 & 428 & 20 & 20.0063 \\
\hline 200 & 0.06 & 0.5 & 40 & 75 & 65 & 428 & 20 & 20.0003 \\
\hline 400 & 0.10 & 0.5 & 60 & 110 & 85 & 428 & 20 & 19.9987 \\
\hline 300 & 0.08 & 0.5 & 50 & 85 & 90 & 428 & 20 & 20.0088 \\
\hline 300 & 0.08 & 0.5 & 45 & 85 & 90 & 428 & 20 & 20.0090 \\
\hline 400 & 0.06 & 0.5 & 40 & 95 & 75 & 428 & 20 & 19.9952 \\
\hline 500 & 0.08 & 0.5 & 50 & 105 & 40 & 428 & 20 & 19.9911 \\
\hline 200 & 0.10 & 0.5 & 60 & 110 & 90 & 428 & 20 & 19.9997 \\
\hline 400 & 0.08 & 0.5 & 55 & 100 & 90 & 428 & 20 & 19.9989 \\
\hline 500 & 0.10 & 0.5 & 50 & 110 & 95 & 428 & 20 & 20.0089 \\
\hline 200 & 0.10 & 0.5 & 45 & 105 & 85 & 428 & 20 & 19.9977 \\
\hline 450 & 0.10 & 1 & 115 & 250 & 105 & 428 & 20 & 19.9937 \\
\hline 300 & 0.10 & 0.5 & 45 & 105 & 110 & 428 & 20 & 19.9993 \\
\hline 300 & 0.10 & 0.5 & 40 & 105 & 105 & 428 & 20 & 20.0005 \\
\hline 200 & 0.06 & 0.5 & 35 & 70 & 65 & 428 & 20 & 19.9981 \\
\hline 500 & 0.06 & 0.5 & 45 & 90 & 70 & 428 & 20 & 20.0094 \\
\hline 200 & 0.08 & 0.5 & 40 & 80 & 75 & 428 & 20 & 20.0015 \\
\hline 200 & 0.08 & 0.5 & 50 & 90 & 75 & 428 & 20 & 20.0010 \\
\hline 400 & 0.20 & 0.5 & 75 & 195 & 115 & 428 & 20 & 20.0011 \\
\hline 300 & 0.25 & 0.5 & 70 & 225 & 140 & 428 & 20 & 20.0029 \\
\hline 200 & 0.20 & 0.5 & 50 & 190 & 125 & 428 & 20 & 19.9978 \\
\hline 200 & 0.20 & 0.5 & 120 & 190 & 130 & 428 & 20 & 19.9976 \\
\hline 400 & 0.25 & 0.5 & 80 & 230 & 125 & 428 & 20 & 19.9992 \\
\hline 300 & 0.20 & 0.5 & 65 & 185 & 130 & 428 & 20 & 20.0018 \\
\hline 500 & 0.25 & 0.5 & 60 & 215 & 115 & 428 & 20 & 20.0039 \\
\hline 500 & 0.20 & 0.5 & 60 & 195 & 110 & 428 & 20 & 19.9967 \\
\hline 200 & 0.25 & 0.5 & 85 & 220 & 160 & 428 & 20 & 19.9943 \\
\hline 200 & 0.25 & 0.5 & 60 & 210 & 150 & 35 & 20 & 19.9939 \\
\hline 450 & 0.10 & 0.5 & 60 & 105 & 55 & 92 & 30 & 29.9956 \\
\hline 350 & 0.10 & 0.5 & 55 & 140 & 85 & 75 & 30 & 30.0011 \\
\hline 450 & 0.10 & 1.5 & 130 & 345 & 115 & 65 & 30 & 29.9910 \\
\hline 450 & 0.10 & 2 & 100 & 450 & 140 & 60 & 30 & 29.9905 \\
\hline 450 & 0.10 & 1 & 100 & 250 & 105 & 70 & 40 & 39.9957 \\
\hline 400 & 0.10 & 0.5 & 55 & 110 & 85 & 129 & 45 & 45.0029 \\
\hline 350 & 0.10 & 0.5 & 60 & 120 & 100 & 42 & 45 & 45.0050 \\
\hline
\end{tabular}




\begin{tabular}{ccccccccc}
\hline 450 & 0.10 & 0.5 & 25 & 85 & 70 & 111 & 55 & 54.9930 \\
450 & 0.10 & 2 & 160 & 470 & 140 & 85 & 55 & 54.9988 \\
350 & 0.10 & 0.5 & 60 & 125 & 100 & 165 & 60 & 66.0085 \\
450 & 0.10 & 1.5 & 150 & 330 & 105 & 94 & 65 & 64.9996 \\
350 & 0.10 & 0.5 & 60 & 125 & 80 & 202 & 75 & 75.0091 \\
450 & 0.10 & 1 & 115 & 260 & 110 & 110 & 75 & 75.0080 \\
450 & 0.10 & 0.5 & 25 & 90 & 70 & 149 & 80 & 80.0047 \\
450 & 0.10 & 2 & 110 & 470 & 140 & 110 & 80 & 79.9965 \\
400 & 0.10 & 0.5 & 50 & 105 & 80 & 240 & 90 & 90.0081 \\
350 & 0.10 & 0.5 & 55 & 130 & 85 & 85 & 90 & 90.0097 \\
450 & 0.10 & 0.5 & 60 & 125 & 105 & 180 & 90 & 89.9936 \\
\hline
\end{tabular}
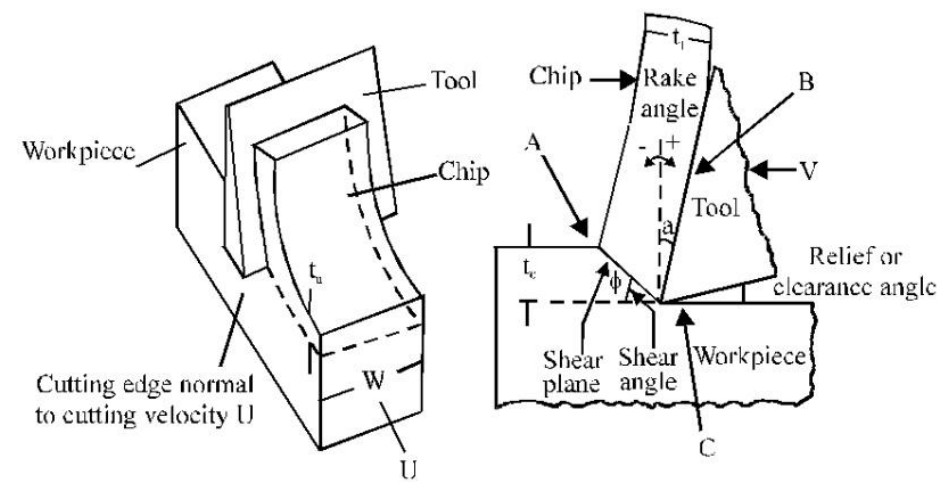

Figure (1): Orthogonal cutting model.
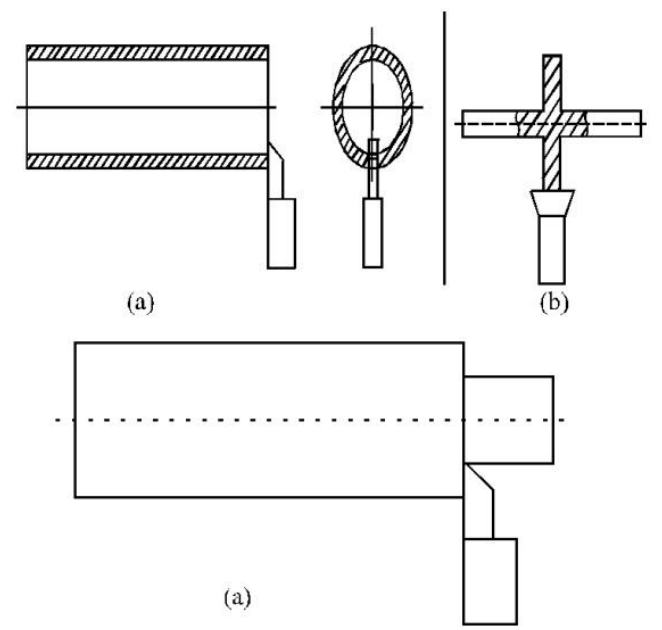

Figure (2): Three turning operations often used in experiment to achieve the orthogonal cutting condition, a): Orthogonal cutting condition via turning a hollow thin-walled tube from one end, b): Orthogonal cutting condition via turning a thin round disk on a solid bar and c): Conventional turning (bar turning) condition. 


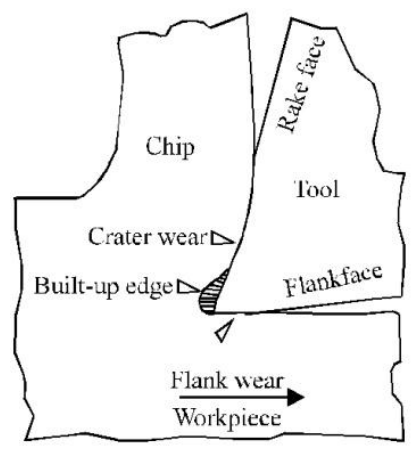

(a)

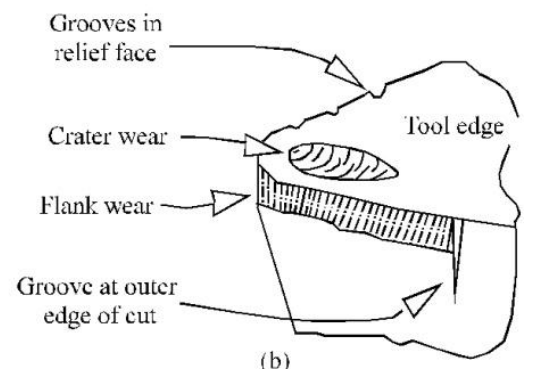

(b)

Figure (3): Basic tool wear modes and their locations on a cutting insert

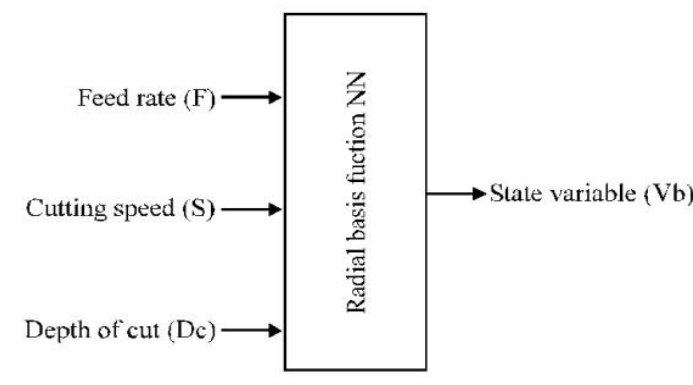

Figure (4): RBFANN for paddle cantilever.

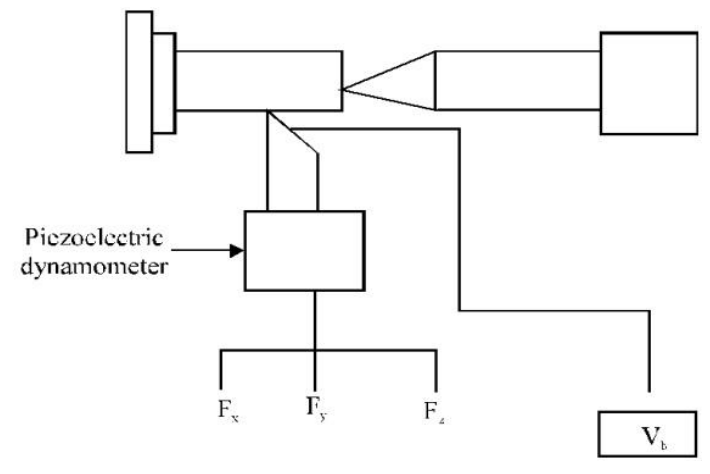

Figure (5): Block diagram of experimental setup.

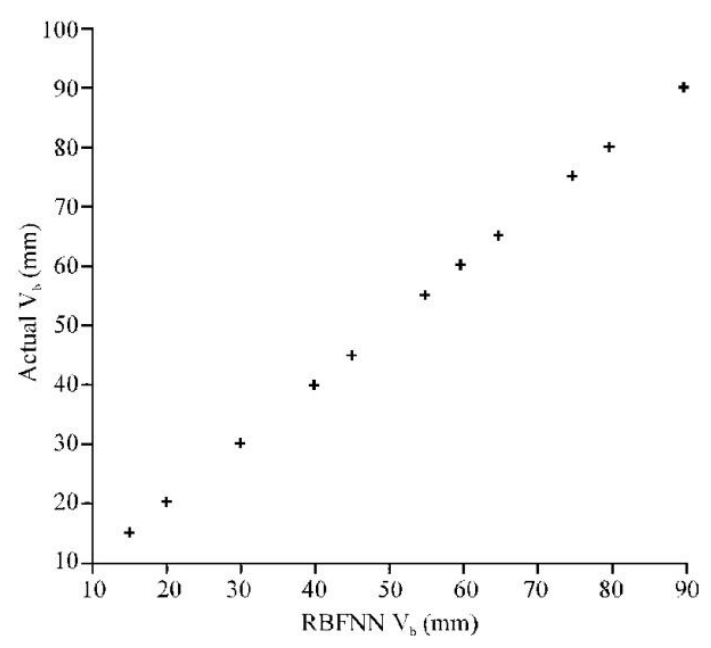

Figure (6): Comparisons between the RBFNN output prediction and actual results RBFNN 
استخدام التقنية الذكية للتنبؤ بتأكل اداة قطع اثثاء الخراطة القاسية

\author{
عقيل علي وناس \\ قسم هندسة المكائن والمعدات/ الجامعة التكنولوجية
}

الخلاصة

تكنولوجيا الخراطة القاسية كانت مقبولة في العديد من الصناعات حتى العقدين الماضيين، اما اليوم فألاتجاه

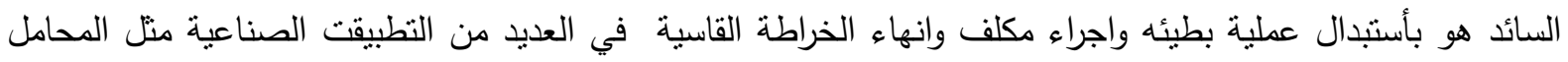

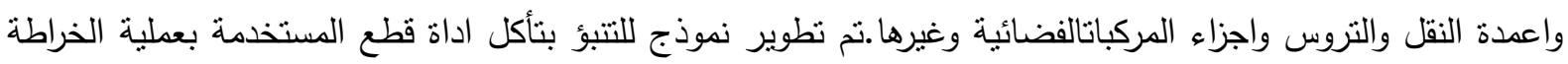

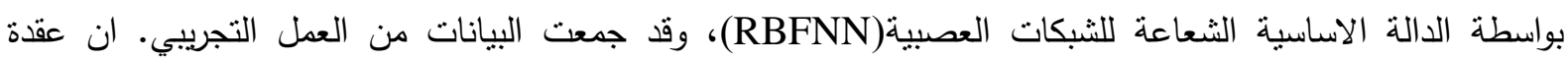

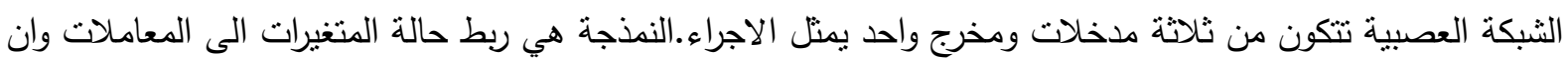

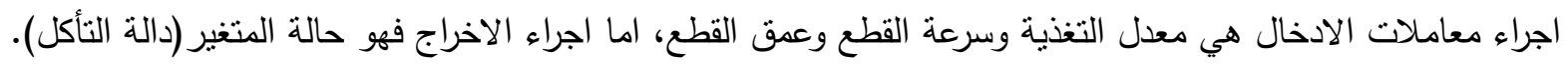
تم تحليل الانحدار بين نتائج العناصر الحددة ونموذج الثبكة العصبية الذي بين اقل خطأ. 